\title{
TENDÊNCIA EMPREENDEDORA: UMA ANÁLISE DO PERFIL DOS PARTICIPANTES DO PROGRAMA MARINHEIRO EMPREENDEDOR
}

Roosiley Santos Souza ${ }^{1}$

Nortonciste Guedes Da Silva Júnior ${ }^{1}$

${ }^{1}$ Universidade Federal de Mato Grosso do Sul 


\section{TENDÊNCIA EMPREENDEDORA: UMA ANÁLISE DO PERFIL DOS PARTICIPANTES DO PROGRAMA MARINHEIRO EMPREENDEDOR}

Resumo: O presente estudo utilizou-se do teste Tendência Empreendedora Geral - TEG (Caird, 2008) para traçar o perfil empreendedor e de tal modo desenvolver atividades no Programa Marinheiro Empreendedor que estimulasse e/ou aprimorasse as características empreendedoras. Identificou-se inicialmente o perfil empreendedor, ajustou o conteúdo programático do programa para alcançar os objetivos propostos. Ao fim do programa, o teste TEG foi reaplicado, estabelecendo uma análise comparativa. Tratou-se de uma pesquisa descritiva de caráter exploratório, apoiada em uma abordagem quali-quantitativa. A amostra foi não probabilística intencional. A análise das médias obtidas em cinco características comuns aos empreendedores: necessidade de sucesso, tendência criativa, necessidade de autonomia, propensão a riscos e impulso/determinação, possibilitou identificar o perfil dos marinheiros antes do contato com conteúdos relacionados a educação empreendedora e após contato. A comparação entre o nível inicial e final de empreendedorismo, evidenciou a importância da educação empreendedora na formação do perfil empreendedor.

Palavras-chave: Tendência Empreendedora. Educação Empreendedora. Programa Marinheiro Empreendedor. Empreendedorismo.

\section{$1 \quad$ Introdução}

O Programa Marinheiro Empreendedor foi um programa piloto desenvolvido a partir de uma demanda do Comando do Sexto Distrito Naval - Marinha do Brasil, no município de Ladário, no estado de Mato Grosso do Sul (MS), com o objetivo de proporcionar aos marinheiros RM2 uma qualificação que permitisse atender as exigências do mercado. Os marinheiros RM2 são aqueles que tem um período de oito anos, prestando serviço em diversas aéreas na Organização Militar (OM), período considerado de muito aprendizado e de desenvolvimento de competências. Porém, foi detectado pelos comandantes das OM's que faltava algum tipo de qualificação que pudesse desenvolver um perfil empreendedor e assim entregar ao mercado e para as organizações civis pessoas com a capacidade de serem protagonistas do seu próprio desenvolvimento e assim contribuir para o incremento da região.

Diante da necessidade exposta, foi estabelecida uma parceria entre o Sexto Distrito Naval de Ladário e a Universidade Federal de Mato Grosso do Sul - Campus do Pantanal para que um programa piloto fosse construído. A construção do programa foi alicerçada conforme os preceitos de Fayolle e Gailly (2008), que se centra nos programas, em que os questionamentos que devem ser respondidos são direcionados para questões como: Por quê? Para quem? Para que resulta? O que? Como?

Para subsidiar a construção do programa utilizou-se do teste Tendência Empreendedora Geral (TEG), que trata de cinco dimensões, a saber: Necessidade de Sucesso/Realização, Necessidade de Autonomia/Independência, Tendência Criativa, Propensão a Riscos, Impulso/Determinação. O teste foi desenvolvido na Durham University Business School, na 
Inglaterra por Caird (1991) e, desde então, tem fomentado o interesse por aqueles que buscam por meio desse teste diagnosticar e potencializar as áreas de empreendedorismo e inovação, na formação de profissionais.

\section{Referencial Teórico}

\subsection{Tendência Empreendedora Geral}

Tendência Empreendedora Geral - TEG, é um teste que foi desenvolvido na Durham University Business School, na Inglaterra por Caird (1991). Para o autor, os empreendedores possuem um conjunto de características e/ou tendências intrínsecos que os distinguem das outras pessoas. Para Caird (1988) todas as pessoas apresentam algumas características empreendedoras em seu perfil comportamental, sendo que, para tanto, basta saber se a quantidade de características apresentadas é suficiente para que o indivíduo possa ser considerado um possível empreendedor de sucesso.

O modelo proposto por Caird (1991) possui as seguintes dimensões:

a) Necessidade de Sucesso/Realização - De acordo com o autor "as pontuações baixas remetem a indivíduos que demonstram características voltadas para a falta de ambição e objetivos" (CAIRD, 1991). Os conhecimentos necessários para melhorar a dimensão são: necessidade de autoconhecimento, planejamento, tomada de decisão, iniciativa, resolução de problemas, inovação e determinação. A pontuação elevada nesta dimensão reflete uma orientação para a tarefa, forte ética no trabalho, desenvolvimento de metas desafiadoras.

b) Necessidade de Autonomia/Independência: a pontuação mais baixa quando se remete a indivíduos com flexibilidade na tomada de decisões, uma preferência na realização de trabalhos para outras pessoas ao invés de cargos de gerência (CAIRD, 1991). Caracteriza-se pela iniciativa de iniciar um negócio. A pontuação mais elevada está relacionada à necessidade de fazer as coisas de forma independente, determinada, não convencional e a baixa valorização da realização de trabalhos com pouca autonomia.

c) Tendência Criativa: A interpretação para as pontuações mais elevadas nesta dimensão indica que os indivíduos possuem características voltadas para uma imaginação e orientação inovadora, versatilidade, intuição, uma preferência pelas novidades e uma forte tendência a aplicar suas próprias ideias no ambiente em que está inserido. As pontuações baixas apontam para indivíduos com características comportamentais que sugerem a preferência pela estabilidade, a utilizar ideias de outras pessoas e sem grande potencial imaginativo (CAIRD, 1991).

d) Propensão a Riscos: a propensão ao risco calculada é definida operacionalmente pela capacidade de lidar com informações incompletas e agir de acordo com uma opção arriscada, que requer habilidades a realização de metas desafiadoras por parte dos indivíduos que as vivenciam (CAIRD, 1991). A pontuação elevada demonstra a capacidade de tomar decisões em condições incertas e sem a necessidade exaustiva de reunir informações para o processo de tomada de decisão. As pontuações baixas revelam um comportamento mais cauteloso para o processo de tomada de decisão e uma preferência por ambientes com incerteza reduzida (CAIRD, 1991).

e) Impulso/Determinação: A pontuação mais elevada nesta dimensão pode ser interpretada como indivíduos que tendem a proatividade, crença, conquista de objetivos devido à capacidade e esforço. As pontuações baixas correspondem a indivíduos com uma visão de 
vida não controlada por si, mas por fatores externos, dependência, crença de que o sucesso depende do fator sorte (CAIRD, 1991).

Portanto, este teste permite analisar os traços de perfil empreendedor e vem sendo utilizado pelos autores em estudos locais e em diferentes contextos. O TEG foi aplicado antes de qualquer contato com teorias e/ou atividades pedagógicas que permitissem o desenvolvimento das características empreendedoras. Ao final do programa foi reaplicado para verificação da efetividade do programa, sendo que foi utilizado pela primeira vez para subsidiar as atividades de um programa voltado para o desenvolvimento das caraterísticas empreendedoras.

\subsection{Educação Empreendedora - EE}

A educação empreendedora é o termo utlizado no Brasil, porém, as contribuições de bases oriundas de estudos e pesquisas internacionais tratam como educação para o empreendedorismo.

De acordo com Kuratko (2005) - a educação para o empreendedorismo surgiu em diferentes contextos educacionais, principalmente como rota para desenvolver uma cultura empresarial, para promover a empresa, para criar novos empreendimentos e para fomentar o espírito empreendedor, por meio da educação e da aprendizagem. (KURATKO, 2005).

De acordo com Lopes e Lima (2019):

aprendizagem empreendedora e educação em empreendedorismo é um dos dez temas promissores em termos de pesquisa. [...] Em qualquer perspectiva de intervenção social para o desenvolvimento econômico e social, a EE exerce um papel fundamental[...] (LOPES e LIMA, p.286,2019).

Nessa linha de intervenção social, buscamos entre os estudiosos os que contribuíram com metodologias e quadros conceituais teóricos possibilitando a análise de programas educacionais, proporcionando a evolução no processo de ensino e aprendizagem. Destacam-se Béchard e Grégorie (2005), Liñán (2007) e Fayolle e Gailly (2008).

Béchard e Grégorie (2005) tem o conceito de modelo de ensino no ensino superior; Liñán (2007) apresenta uma contribuição no sentido de avaliar os estágios em que essa educação se desenvolve. Os estudos de Fayolle e Gailly (2008) centra-se nos programas propriamente ditos, em que os questionamentos que devem ser respondidos são direcionados para questões como: Por quê? Para quem? Para que resulta? O que? Como? Que pode ser mais bem compreendido no quadro 1 em que se apresenta o Modelo Teórico desse autor.

Quadro 1 - Modelo Teórico Fayolle e Gailly

\begin{tabular}{|c|c|c|c|c|}
\hline Autor & Ano & Campo Estudo & $\begin{array}{c}\text { Unidade de } \\
\text { Análise }\end{array}$ & Questões \\
\hline $\begin{array}{l}\text { Fayolle } \\
\text { e Gailly }\end{array}$ & 2008 & Gestão/Empreendedorismo & $\begin{array}{l}\text { Programas de } \\
\text { Educação para o } \\
\text { Empreendedorismo }\end{array}$ & $\begin{array}{l}\text { Por quê? } \\
\text { Para quem? } \\
\text { Para que resulta? } \\
\text { O que? } \\
\text { Como? }\end{array}$ \\
\hline
\end{tabular}

Fonte: Adaptado a partir de Fayolle e Gailly (2008). 
Fayolle e Gailly (2008),

[...] definem educação para o empreendedorismo em sentido amplo como qualquer programa pedagógico ou processo de educação para as atitudes e competências empresariais, que envolve o desenvolvimento de certas qualidades pessoais. [...] Assim, esta definição abrange uma ampla variedade de situações, objetivos, métodos e abordagens de ensino. [...] (FAYOLLE e GAILLY, 2008)

A análise do modelo e programa adotado no desenvolvimento da educação para o empreendedorismo, segundo Fayolle e Gailly (2008), contribuem para uma análise do que realmente está sendo proporcionado aos estudantes em termos de educação para o empreendedorismo. Para tanto, as questões que nortearam o programa são:

- Por quê? - necessidade de elaborar um programa de educação para o empreendedorismo;

- Para quem? - destaca a necessidade de se adaptar às características (experiência empresarial anterior ao conhecimento, nível de envolvimento e compromisso no processo empreendedor).

- Para que resulta? - salienta a importância da avaliação de programas de ensino a partir de sua concepção, definição dos critérios de avaliação (conhecimentos, habilidades, intenção e motivação), bem como métodos de medição.

- O que? - refere-se a conteúdos de ensino

- Como? - refere-se a métodos de ensino.

Para os autores acima citados, a educação para o empreendedorismo deve ter aprendizado (macro / sociedade) e objetivos socioeconômicos (micro / indivíduo). Nessa linha Krakauer et al (2015), diz que: a educação empreendedora além de incentivar o comportamento empreendedor capacitando o aluno para o mercado de trabalho também amplia as formas de encarar um negócio próprio, atendendo uma demanda já existente ou estruturando um novo negócio com melhorias no serviço já oferecido (KRAKAUER et al., 2015).

Perante as recomendações dadas pelo autor de base, na sequência apresentamos o projeto piloto Programa Marinheiro Empreendedor.

\subsection{Programa Marinheiro Empreendedor}

Trata-se de um programa piloto com o título de 'PROGRAMA MARINHEIRO EMPREENDEDOR", que foi desenvolvido com foco no indivíduo em relação ao ambiente e o potencial deste indivíduo para empreender, visando desenvolver competências necessárias para a formação empreendedora dos Marinheiros, esses que possuem contratos temporários de serviço com a Marinha do Brasil no âmbito do Sexto Distrito Naval de Ladário - Mato Grosso do Sul, denominados de "RM2".

A construção da metodologia do programa seguiu o modelo de Fayolle e Gailly (2008):

- Por quê? - para atender a necessidade de um programa de educação empreendedora para os Marinheiros "RM2", surgiu o desenvolvimento do programa;

- Para quem? - para um grupo de marinheiros pré-selecionados entre as OM's cujo perfil 
fosse de envolvimento e compromisso com o processo empreendedor proposto.

- Para que resulta? - o uso do TEG como método de medição permitiu ressaltar a importância da avaliação de programas de ensino a partir de sua concepção.

- O que? - desenvolvimento de conteúdos que permitissem o aprender a empreender.

- Como? - os métodos de ensino baseado no aprender fazendo.

Diante do exposto, o objetivo do programa foi fornecer conhecimentos sobre o processo de Empreender e Inovar possibilitando aos participantes o desenvolvimento de um plano empreendedor, inovador e de acordo com as possibilidades de modelos de negócios sustentáveis para a região.

Inicialmente, o programa teve uma estrutura pensada de acordo com a demanda apresentada, sendo aperfeiçoada com a identificação do perfil dos participantes. O perfil encontrado demonstrou a necessidade de melhorar as seguintes dimensões: necessidade de autonomia/independência, tendência criativa e propensão a riscos. O programa foi conduzido utilizando a metodologia fundamentada no aprender fazendo, conforme as etapas abaixo apresentadas:

1. Integração e formação das equipes de trabalho;

2. Apresentação de vídeos e dinâmicas que fizessem entender sobre o processo de empreender;

3. Pensando no negócio para a região com base na Teoria do Effectuation - "Quem eu sou", "O que eu sei" e "Quem eu conheço".

4. Trabalhando a ideia de negócio e colocando no papel;

5. Como planejar o negócio e o marketing dele;

6. Quanto custaria a ideia do negócio pensado;

7. Repensando os custos e o uso das tecnologias para desenvolvimento do negócio, com palestras nas áreas sobre finanças e o uso de tecnologias disponíveis no mercado;

8. Apresentação e validação da ideia de negócio para uma banca avaliadora formada por profissionais do mercado dos setores dos negócios pensados e por agentes de instituições financeiras;

9. Feedback sobre as observações das ideias de negócios recebidas pela banca;

10. Reavaliação das ideias de negócios;

O Programa teve ao todo sete encontros, ocorrendo entre os meses de agosto e setembro

do corrente ano, aos sábados no período da tarde, com um intervalo de uma semana entre os dois últimos encontros.

\section{$3 \quad$ Metodologia}

A pesquisa é exploratória, e tem o intuito de obter maior conhecimento sobre o assunto. A fundamentação teórica baseou-se nos estudos de Peloggia (2001), Ferreira e Aranha (2008), Espírito Santo (2011), Souza et al (2014) e Assad (2016) e em pesquisa bibliográfica em relatórios de estudos na área e artigos sobre o tema em estudo. Primeiro momento utilizou-se o levantamento de fontes secundárias através de pesquisa bibliográfica e, em segundo momento, houve a coleta de dados primários através da aplicação de um questionário socioeconômico. $\mathrm{O}$ questionário foi constituído de questões fechadas que, segundo Gil (2008) conferem maior uniformidade às respostas e podem ser facilmente processadas. O questionário foi aplicado simultaneamente com o teste de TEG. A aplicação do questionário e do teste TEG deu-se por 
meio impresso, no primeiro encontro do Programa Marinheiro Empreendedor, a segunda aplicação do Teste TEG ocorreu no último dia do encontro.

O TEG consiste em um instrumento de coleta de dados composto por 54 afirmações, em que os respondentes manifestam sua concordância ou discordância.

Seguindo o método empregado por Peloggia (2001), a tabulação dos dados, tiveram as seguintes etapas:

1. O cartão resposta é composto por áreas sombreadas e não sombreadas. Deve-se anotar 1 ponto para cada "não concordo" (N) assinalado nas casas sombreadas e 1 ponto para cada "concordo" $(\mathrm{C})$ assinalado nas casas não sombreadas.

2. A pontuação deve ser somada por linha e anotada.

3. Em seguida, é feito o lançamento dessa pontuação por linha em uma tabela com duas colunas, sendo uma coluna com o número da linha e outra coluna com a pontuação obtida, de forma a facilitar a visualização.

4. Os pontos obtidos nas linhas serão somados e atribuídos às suas respectivas características, conforme indicado no quadro 02:

Quadro 2: Metodologia de tabulação do TEG

\begin{tabular}{|c|l|}
\hline Linhas & Características \\
\hline $\mathbf{1 + 6}$ & Necessidade de sucesso \\
\hline $\mathbf{3}$ & Necessidade de autonomia/independência \\
\hline $\mathbf{5 + 8}$ & Tendência criativa \\
\hline $\mathbf{2 + 9}$ & Propensão a riscos \\
\hline $\mathbf{4 + 7}$ & Impulso e determinação \\
\hline
\end{tabular}

Fonte: Adaptado de Peloggia (2001, p.45-46)

As médias propostas por Caird (1991) ao desenvolver o Teste TEG e apresentadas por Ferreira e Aranha (2008), serão utilizadas como parâmetros de análise das médias obtidas com a presente pesquisa, conforme o quadro 3:

Quadro3: Metodologia para análise da média das cinco características do perfil empreendedor.

\begin{tabular}{|l|r|r|}
\hline Característica & $\begin{array}{r}\text { Pontuação } \\
\text { Máxima }\end{array}$ & $\begin{array}{r}\text { Média } \\
\text { Esperada }\end{array}$ \\
\hline Necessidade de sucesso & 12 & 9 \\
\hline Necessidade de autonomia/independência & 6 & 4 \\
\hline Tendência criativa & 12 & 8 \\
\hline Propensão a riscos & 12 & 8 \\
\hline Impulso e determinação & 12 & 8 \\
\hline
\end{tabular}

Fonte: Adaptado de Ferreira e Aranha (2008, p. 5) 
A pesquisa é de cunho descritivo, que segundo Cervo e Bervian (2002, p. 66) a pesquisa de natureza descritiva tem o intuito de "procurar descobrir, com a precisão possível, a frequência com que um fenômeno ocorre, sua relação e conexão com outros, sua natureza e características". O universo de abrangência do estudo compreendeu os sujeitos sociais na figura dos marinheiros "RM2".

Como critério da seleção da amostra, aplicou-se a pesquisa no primeiro encontro ocorrido em 03 de agosto e no último encontro que aconteceu em 28 de setembro, assim, a seleção da amostra foi feita de maneira não probabilística e intencional, tendo em vista os fatores de acessibilidade e disponibilidade dos respondentes.

A análise dos dados valeu-se das informações quantitativas oriundas da tabulação do instrumento de pesquisa, auxiliada pela metodologia de Peloggia (2001), conforme as fases explicitadas no quadro 2 .

A metodologia utilizada para análise dos dados quantitativos foi a estatística descritiva básica com auxílio do software Microsoft Excel, com base na média das cinco características do perfil empreendedor explicitadas no quadro 3 de Ferreira e Aranha (2008).

\section{$4 \quad$ Apresentação dos Resultados e análise}

Os resultados foram apresentados em cinco partes. Na primeira constam as características gerais do Comando do Sexto Distrito Naval de Ladário, buscando contribuir para melhor entendimento do contexto do estudo. Em seguida, os resultados sobre o perfil socioeconômico dos respondentes, o TEG Inicial versus TEG Final, o TEG dos Marinheiros RM2 analisados, a comparação com os estudos locais realizados sobre o tema, são evidenciados.

4.1 Comando do Sexto Distrito Naval de Ladário - Marinha do Brasil

O Comando do Sexto Distrito Naval é uma Organização Militar da Marinha do Brasil, localizada no município de Ladário, no Estado de Mato Grosso do Sul, na Região Centro Oeste do País. De acordo com o histórico do Comando do Sexto Distrito Naval, sua construção foi determinada em 07 de janeiro de 1733, com lançamento da pedra fundamental em 14 de março do mesmo ano. Teve vida própria a partir de 1933, ano que passou a ser considerado como Comando Naval de Mato Grosso e teve sua denominação alterada em 1945 para Base Fluvial de Ladário e, nesse mesmo ano, o Comando Naval de Mato Grosso passou a denominar-se Sexto Distrito Naval. Tem jurisdição sobre os Estados de Mato Grosso e Mato Grosso do Sul.

\subsection{Perfil Socioeconômico dos Respondentes}

De acordo com os resultados obtidos na pesquisa, o gênero predominante no Programa Marinheiro Empreendedor é o gênero masculino, faixa etária predominante 61,12\% entre 26 30 anos, 38,88\% entre $21-25$ anos. O estado civil predominante é o solteiro, o que corresponde a $55,56 \%$, e os casados são 44,44\%. Todos desempenham atividades laborais nas seguintes OM's: Centro de Intendência (CeIMla), Base Fluvial (BFLa), Capitania Fluvial (CFPN), Esquadrão de Helicópteros (EsqdHU-4), Hospital Naval (HNFLa), Comando da Flotilha (ComFlotMT), Grupamento de Fuzileiros Navais (GptFNLa), Serviço de Sinalização Náutica (SSN-6) e Comando do Sexto Distrito Naval $\left(\mathrm{Com}^{\circ} \mathrm{DN}\right)$. A renda mensal própria dos marinheiros predominantemente de $100 \%$ encontra-se na faixa de 01 a 05 salários mínimos $(\mathrm{R} \$ 998,00$ - $\mathrm{R} \$ 4.990,00)$, quando perguntado sobre a renda familiar, predomina em $88,89 \%$ na 
faixa de 01-05 salários mínimos e 11,11\% na faixa de 05 - 10 salários mínimos ( $\$ 4$ 4990,00 $\mathrm{R} \$ 9.980,00)$.

\subsection{TEG dos Marinheiros RM2 - Inicial versus Final}

Este item busca analisar a Tendência Empreendedora Geral (TEG) dos Marinheiros "RM2" a partir do modelo proposto por Caird (1991), objetivo este que norteia o presente estudo. A seguir, a Tabela 1 apresenta as médias obtidas e as médias esperadas a partir da percepção dos 28 vendedores ambulantes analisados.

Tabela 1: Apresentação das médias iniciais dos participantes do Programa Marinheiro Empreendedor

Características Pontuação Máxima Média Esperada $\begin{gathered}\text { Média Inicial da } \\ \text { turma }\end{gathered}$

\begin{tabular}{|c|c|c|c|}
\hline Necessidade de sucesso & 12 & 9 & 8,62 \\
\hline $\begin{array}{c}\text { Necessidade de } \\
\text { autonomia/independência }\end{array}$ & 6 & 4 & 2,71 \\
\hline Tendência criativa & 12 & 8 & 6,9 \\
\hline Propensão a riscos & 12 & 8 & 7,38 \\
\hline Impulso e determinação & 12 & 8 & 8,48 \\
\hline
\end{tabular}

Fonte: Dados da pesquisa

De acordo com a Tabela 1, as médias mais baixas e que necessitavam de um tratamento durante o programa para melhorar e chegar o mais próximo da média esperada, foram: a dimensão Necessidade de autonomia/interdependência, que para Dornelas (2014) essa característica define o indivíduo empreendedor como aquele que tem a necessidade de estar sempre à frente das mudanças e de ser dono do próprio destino; Tendência criativa: Segundo Espírito Santo (2011), essa característica estimula a capacidade de raciocínio alternativo, de usar a criatividade para sair de dificuldades ou até mesmo para aumentar os lucros. Propensão a riscos: Segundo Dornelas (2014), é a pessoa que tem tendência a estabelecer metas desafiadoras, porém realistas, assumindo riscos calculados e avaliando as possibilidades de sucesso. O que justificaria essas médias, o fato de os pesquisados possuírem no momento uma carreira no serviço público, uma certa estabilidade, o que preocupa, pois eles são temporários e terão que enfrentar o mercado. Motivo que levou ao desenvolvimento do programa na expectativa de apresentar oportunidades pós período Marinha.

Observa-se na tabela 2, que ocorreram mudanças em todas as médias, em especial as três que se apresentaram abaixo da média no TEG inicial. 
Tabela 2: Apresentação das médias finais dos participantes do Programa Marinheiro Empreendedor
Características
Pontuação Máxima
Média Esperada
Média Final da turma

\begin{tabular}{|l|c|c|c|}
\hline Necessidade de sucesso & 12 & 9 & 9,50 \\
\hline $\begin{array}{l}\text { Necessidade de } \\
\text { autonomia/independência }\end{array}$ & 6 & 4 & 3,14 \\
\hline Tendência criativa & 12 & 8 & 7,36 \\
\hline Propensão a riscos & 12 & 8 & 8,27 \\
\hline Impulso e determinação & 12 & 8 & 9,50 \\
\hline
\end{tabular}

Fonte: Fonte: Dados da pesquisa

O quadro 6, apresenta a comparação entre as médias iniciais e finais e seu percentual de crescimento entre os participantes do Programa Marinheiro Empreendedor. Ocorreu um aumento em todas as médias, em especial aquelas que se apresentaram abaixo do esperado. As medias iniciais tiveram os seguintes aumentos: Necessidade de autonomia/interdependência de 2,71 para 3,14 o que equivale um aumento de $6,25 \%$ se comparado a média inicial; Tendência criativa, de 6,90 para 7,36 , o que equivale dizer que obteve um aumento de $6,25 \%$ e a Propensão a riscos de 7,38 para 8,27, representando um aumento de $10,76 \%$. Abaixo o quadro 6 apresenta esses resultados.

Quadro 6: Apresentação das comparações entre as médias iniciais e finais

\begin{tabular}{|l|c|c|c|c|c|}
\hline \multicolumn{1}{|c|}{ Dimensões } & $\begin{array}{c}\text { Pontuacao } \\
\text { Maxima }\end{array}$ & $\begin{array}{c}\text { Media } \\
\text { Esperada }\end{array}$ & $\begin{array}{c}\text { Media Inicial do } \\
\text { Programa } \\
\text { "Marinheiro }\end{array}$ & $\begin{array}{c}\text { Media Finaldo } \\
\text { Programa } \\
\text { "Marinheiro }\end{array}$ & $\begin{array}{c}\text { Percentual de } \\
\text { Crescimento }\end{array}$ \\
\hline Necessidade de sucesso & 12,00 & 9 & 8,62 & 9,50 & $9,26 \%$ \\
\hline $\begin{array}{l}\text { Necessidade de } \\
\text { autonomialindependência }\end{array}$ & 6,00 & 4 & 2,71 & 3,14 & $6,25 \%$ \\
\hline Tendência criativa & 12,00 & 8 & 6,90 & 7,36 & $6,25 \%$ \\
\hline Propensão a riscos & 12,00 & 8 & 7,38 & 8,27 & $10,76 \%$ \\
\hline Impulso e determinação & 12,00 & 8 & 8,48 & 9,50 & $10,74 \%$ \\
\hline
\end{tabular}

Fonte: Fonte: Dados da pesquisa

A Figura 1 ilustra a Tendência Empreendedora Geral dos Marinheiros RM2 do Programa Marinheiro Empreendedor, obtido através do estudo de dados secundários disponíveis. As dimensões em que o gráfico se encontra mais longe do centro são aquelas onde as dimensões são mais intensas. 


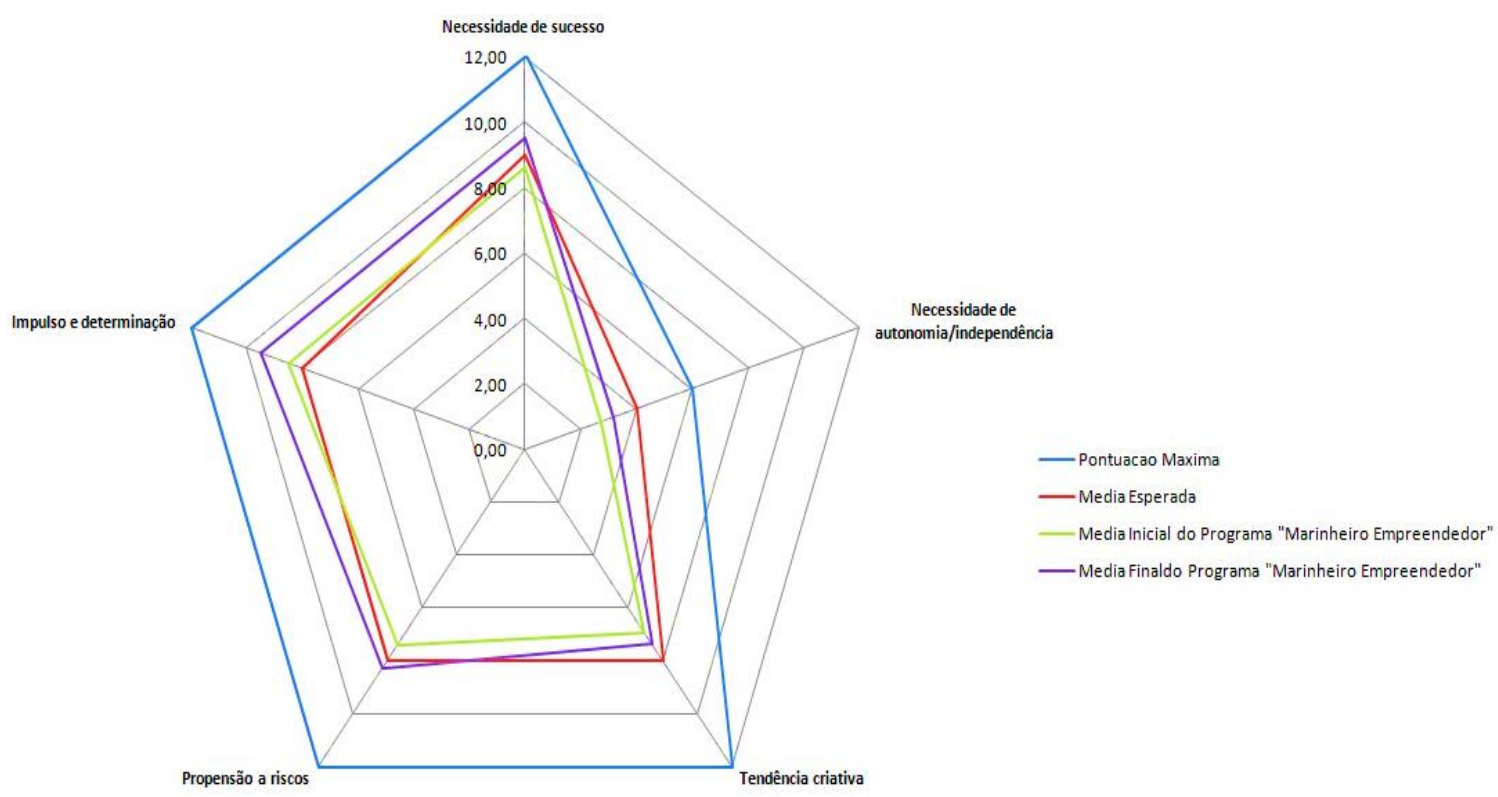

Figura 1 - Tendência Empreendedora Geral dos Marinheiros RM2 do Programa Marinheiro Empreendedor

Fonte: Dados da pesquisa

4.5. Quadro dos dados achados da pesquisa com os estudos empíricos locais desenvolvidos em âmbito empresarial e escolar.

Na sequência, o quadro 7 evidencia a comparação dos achados desta pesquisa junto aos Marinheiros RM2 com os estudos empíricos anteriores desenvolvidos em âmbito empresarial que utilizaram o modelo de Caird (1991).

Quadro 7: Comparação entre estudos empíricos em âmbito empresarial e o Programa Marinheiro Empreendedor

\begin{tabular}{|c|c|c|c|c|c|c|c|c|}
\hline Dimensões & $\begin{array}{l}\text { Pontuacao } \\
\text { Maxima }\end{array}$ & $\begin{array}{c}\text { Media } \\
\text { Esperada }\end{array}$ & $\begin{array}{l}\text { Souza et al } \\
(2014)\end{array}$ & $\begin{array}{l}\text { Samaniego } \\
\text { (2014) }\end{array}$ & $\begin{array}{c}\text { Amorim } \\
(2015)\end{array}$ & $\begin{array}{c}\text { Espirito } \\
\text { Santo (2015) }\end{array}$ & $\begin{array}{l}\text { Media Inicial do } \\
\text { Programa } \\
\text { "Marinheiro } \\
\text { Empreendedor" } \\
\end{array}$ & $\begin{array}{c}\text { Media Final do } \\
\text { Programa } \\
\text { "Marinheiro } \\
\text { Empreendedor" }\end{array}$ \\
\hline Necessidade de sucesso & 12,00 & 9 & 7,21 & 8,70 & 8,14 & 8,11 & 8,62 & 9,50 \\
\hline \begin{tabular}{|l|} 
Necessidade de \\
autonomia/independência
\end{tabular} & 6,00 & 4 & 3,32 & 3,68 & 3,43 & 2,83 & 2,71 & 3,14 \\
\hline Tendência criativa & 12,00 & 8 & 6,39 & 4,90 & 6,64 & 6,66 & 6,90 & 7,36 \\
\hline Propensão a riscos & 12,00 & 8 & 6,32 & 5,74 & 7,36 & 6,19 & 7,38 & 8,27 \\
\hline Impulso e determinação & 12,00 & 8 & 6,85 & 9,45 & 9,43 & 9,28 & 8,48 & 9,50 \\
\hline
\end{tabular}

Fonte: Dados coletados pelos autores

Os resultados obtidos com o Programa demonstram dados significativos de que todas as atividades desenvolvidas no curso estimularam o desenvolvimento das dimensões que caracterizam o perfil empreendedor medido pelo teste da Tendência Empreendedora Geral. 
Na sequência, quadro 8 com comparações entre estudos no âmbito escolar.

Quadro 8: Comparação entre estudos empíricos em âmbito escolar e o Programa Marinheiro Empreendedor

\begin{tabular}{|l|c|c|c|c|c|c|c|c|}
\hline \multicolumn{1}{|c|}{ Dimensões } & $\begin{array}{c}\text { Pontuacao } \\
\text { Maxima }\end{array}$ & $\begin{array}{c}\text { Media } \\
\text { Esperada }\end{array}$ & $\begin{array}{c}\text { Espirito Santo } \\
\text { (2011) }\end{array}$ & Silva (2016) & $\begin{array}{c}\text { Assad (2016) } \\
\text { ADM }\end{array}$ & $\begin{array}{c}\text { Assad (2016) } \\
\text { CC }\end{array}$ & $\begin{array}{c}\text { Média Inicial do } \\
\text { Programa } \\
\text { "Marinheiro } \\
\text { Empreendedor" }\end{array}$ & $\begin{array}{c}\text { Média Final do } \\
\text { Programa } \\
\text { "Marinheiro } \\
\text { Empreendedor" }\end{array}$ \\
\hline Necessidade de sucesso & 12,00 & 9 & 8,85 & 8,57 & 8,68 & 8,05 & 8,62 & 9,50 \\
\hline $\begin{array}{l}\text { Necessidade de } \\
\text { autonomialindependência }\end{array}$ & 6,00 & 4 & 3,45 & 3,42 & 3,23 & 2,40 & 2,71 & 3,14 \\
\hline Tendência criativa & 12,00 & 8 & 6,91 & 7,12 & 6,90 & 5,80 & 6,90 & 7,36 \\
\hline Propensão a riscos & 12,00 & 8 & 7,38 & 7,12 & 6,88 & 6,55 & 7,38 & 8,27 \\
\hline Impulso e determinação & 12,00 & 8 & 8,62 & 9,42 & 9,25 & 8,55 & 8,48 & 9,50 \\
\hline
\end{tabular}

Fonte: Dados coletados pelos autores

A apresentação de estudos anteriores sobre o TEG e a comparação com os resultados do programa, permite uma análise ampliada no contexto local.

\section{Considerações Finais}

A proposta do estudo foi alcançada: Traçar o Perfil inicial e final entre os participantes do Programa Marinheiro Empreendedor e desenvolver um programa que além de proporcionar uma educação empreendedora, incentivou o comportamento empreendedor capacitando os participantes Marinheiros RM2 para atuarem no mercado de trabalho e serem protagonistas do seu próprio desenvolvimento. O Marinheiros RM2 apresenta tendência empreendedora geral após uma intervenção educacional.

As comparações com os estudos locais anteriores em contexto escolar e empresarial mostraram que os resultados da presente pesquisa inicial se assemelham aos Souza et al (2014), Samaniego (2014), Amorim (2015), Espírito Santo (2011)/(2015), Silva (2016) e Assad (2016) mesmo que os mesmos tenham sido realizados em contextos diferenciados. Em nenhuma delas a média ultrapassou a média esperada e estipulada pelas dimensões do modelo de Caird (1991).

Ao comparar os mesmos com os resultados obtidos ao final do desenvolvimento do Programa Marinheiro Empreendedor, o programa piloto, conseguiu atingir seus objetivos e principalmente elevar a média de todas as dimensões abordadas pelo TEG.

Para o próximo programa, há uma necessidade de entender e trabalhar a cultura local, uma vez que ela interfere na média continuarem abaixo da média esperada de Necessidade de autonomia/independência e Tendência criativa.

Quanto à metodologia adotada para a pesquisa está se mostrou adequada. Destaco que o número de respondentes corresponde a $75 \%$ dos participantes no programa e foi representativo, oportunizando a medida quantitativa. Da mesma forma a análise dos dados se mostraram pertinentes e representativos para o que se objetivou com este estudo.

Considerando ser este um programa piloto, sua continuidade deve ser assegurada no sentido de proporcionar sua ampliação e aprofundamento, oferecendo um programa 
restruturado e mais amplo com relação ao conteúdo e atividades e aos números de encontros para o desenvolvimento dele.

O Comando do Sexto Distrito Naval, de posse destes resultados iniciais pretende continuar com a parceria e assim oferecer em 2020 um novo programa, com possibilidade de uma maior abrangência, pois o programa piloto atendeu apenas 25 marinheiros de diversas OM's.

A pesquisa aqui relatada evidenciou, por meio de seus resultados, as características e, de certa forma, a importância que estes Marinheiros RM2 representam no momento para a sociedade local.

Finalizando se pode concluir que pesquisas com este potencial devem ser protagonizadas antes da execução dos programas voltados para a educação empreendedora.

Recomendam-se novos estudos e pesquisas orientados para uma nova vertente de estudos sobre a cultura e sua influência para o desenvolvimento de programas de educação empreendedora.

\section{Referências}

ASSAD, Rafaela Esmorges. Tendência empreendedora: uma análise comparativa do perfil empreendedor dos acadêmicos dos cursos de Administração e Ciências Contábeis do Campus Pantanal da Universidade Federal de Mato Grosso do Sul. 2016. 91 fls. Trabalho de Conclusão do Curso de Administração - Universidade Federal de Mato Grosso do Sul Campus do Pantanal, Corumbá-MS, 2016.

BÉCHARD, Jean-Pierre; GRÉGOIRE, Denis. Entrepreneurship education research revisited: the case of higher education. Academy of Management Learning \& Education, v. 4, n. 1, p. 22-43, 2005.

CAIRD, Sally. A review of measuring enterprise attributes. DUBS, august, 1988. General measure of enterprising tendency. In Worldwide Interest in GET, 2008.

Testing enterprising tendency of occupational groups. British Journal of Management, v. 2, p. 177-186. 1991.

CERVO, A. L.: BERVIAN, P. A. Metodologia científica. 5.ed. São Paulo: Pearson Prentice Hall, 2002.

DORNELAS, José Carlos Assis, Empreendedorismo: transformando ideias em negócios / José Carlos Assis Dornelas. - 5. ed. - Rio de Janeiro: Empreende / LTC, 2014

ESPÍRITO SANTO, Michelle Oliveira. Tendência Empreendedora: Uma Análise do Perfil dos Acadêmicos do Curso de Administração em Instituição de Ensino Superior da Cidade de Corumbá-MS. Corumbá: Curso de Administração, Campus do Pantanal, Universidade Federal de Mato Grosso do Sul, 2011, 133 p. Monografia de Graduação.

Empreendedorismo na Administração Púbica: um Estudo do Perfil Empreendedor da Equipe Administrativa de uma Instituição Federal de Ensino Superior, como 
Ferramenta de Melhoria no Desempenho Organizacional. Campo Grande: Mestrado Profissional em Administração Pública em Rede Nacional - PROFIAP, Escola de Administração e Negócios, Universidade Federal de Mato Grosso do Sul, 2015, 80 p. Trabalho de Conclusão Final.

GIL, Antonio Carlos. Métodos e Técnicas de Pesquisa Social. 6.ed. São Paulo: Ed Atlas, 2008 .

FAYOLLE, Alain; GAILLY, Benoit. From craft to science: Teaching models and learning processes in entrepreneurship education. Journal of European Industrial Training, v. 32, n. 7, p. 569-593, 2008.

FERREIRA, R. C.; ARANHA, E. A. Análise do perfil empreendedor de graduados em Engenharia de Produção Mecânica. Universidade Federal de Itajubá. MG: UNIFEII, 2008.

KURATKO, Donald F. The emergence of entrepreneurship education: Development, trends, and challenges. Entrepreneurship: theory \& practice, v. 29, n. 5, p. 577-598, 2005.

KRAKAUER, P. V. C. et al. Ensino de empreendedorismo: utilização do business model generation. Revista de Administração e Inovação, São Paulo, v. 12, n.1, p. 7-23, jan./mar. 2015.

LIÑÁN, Francisco.The role of entrepreneurship education in the entrepreneurial process.2007. Disponível: http://institucional.us.es/vie/documentos/resultados/Linan2007.pdf

LOPES, ROSE; ALMEIDA, MARY; LIMA, EDMILSON. DESAFIOS ATUAIS E CAMINHOS PROMISSORES PARA A PESQUISA EM EMPREENDEDORISMO. Revista de Administração de Empresas, v. 59, n. 4, p. 284-292, 2019. Disponível em: https://rae.fgv.br/rae/vol59-num4-2019/desafios-atuais-caminhos-promissores-para-pesquisaem-empreendedorismo-versao.

PELOGGIA, L. R. Perfil empreendedor do engenheiro na produção industrial: O caso de duas empresas aeronáuticas no Brasil, 2001. 89f. Monografia apresentada ao Curso de MBA em Gerência de Produção e Tecnologia da Universidade de Taubaté: São Paulo, 2001.

SOUZA, Roosiley dos Santos; SILVEIRA, Amélia; NASCIMENTO, Sabrina do; ESPÍRITO SANTO, Michelle Oliveira do. Vendedores Ambulantes e o Modelo de CAIRD (1991): Tendência Empreendedora Geral (TEG). Disponível em http://www.egepe.org.br/anais/tema12/326.pdf 